\title{
A CRITICAL REVIEW OF THE RESULTS OF LUNG RESECTION FOR PULMONARY TUBERCULOSIS *
}

\author{
BY
}

\author{
B. J. BICKFORD, F. RONALD EDWARDS, J. R. ESPLEN, J. H. GIFFORD, \\ O. F. THOMAS, AND J. K. B. WADDINGTON \\ From the Thoracic Surgical Service of the Liverpool Region (Aintree and Broadgreen Hospitals) and the \\ Department of Surgery, University of Liverpool
}

(RECEIVED FOR PUBLICATION DECEMBER 20, 1956)

\begin{abstract}
Between 1947 and April, 1956, 1,575 patients have had pulmonary resection performed in the treatment of tuberculosis at Aintree and Broadgreen Hospitals, Liverpool. During this period, although a certain number of cases of active bilateral disease have been treated by thoracoplasty, resection of the affected area has been the method of choice for the surgical treatment of all types of the disease.
\end{abstract}

In two previous communications (Bickford, Edwards, Esplen, Gifford, Mair, and Thomas, 1951 ; Bickford, Edwards, Esplen, Gifford, and Thomas, 1952) we laid down our principles for undertaking resection, and these have remained basically unchanged to date, except that our views in relation to compensatory space reduction of the thoracic cavity have crystallized in favour of corrective thoracoplasty.

It is probable that during the years our indications for resection have widened somewhat, as it became clear that with sufficient chemotherapeutic control, areas of lung could be removed, leaving active disease behind which might be expected to heal without severe lung damage. The changing face of tuberculosis has resulted in a considerable number of very chronic carriers being submitted to surgery, and many of these cases fall into the above group.

The surgery of the caseous nodule has changed in later years with the development of long-term therapy, and a more conservative approach to these is now being taken. We still believe that a caseous nodule of over $2.5 \mathrm{~cm}$. in diameter should be excised, however much chemotherapy has been given or is proposed in the future.

The use of chemotherapy has so altered the scheme of treatment that surgery must be con-

* Based on a paper given by one of us (F. Ronald Edwards) to the British Tuberculosis Association in July, 1956. sidered as a secondary therapeutic measure, and it is almost impossible in many cases to evaluate its position in the final result.

The pathological picture of some of the removed specimens showing sterilized cavities or the absence of any histological evidence of active disease should indicate caution in evaluating the position of surgery in modern treatment. Nevertheless patients have been submitted for surgery and continue to be presented by physicians in the belief that chemotherapy will not ultimately heal the lesion. Judgment so frequently has to be made on the radiological appearances, as signs of clinical or bacterial activity have disappeared in the early part of the course of treatment. These radiological appearances often have varying interpretations, and it is not at all surprising that occasionally the pathological report is not in conformity.

The development of bacillary resistance to chemotherapy may have a marked impact on the use of resection as a line of treatment, as its success depends greatly on the use of drugs to control transbronchial spread of disease or contamination at the operation site.

In attempting to reach some assessment of the value of resection treatment, a survey has been made of the first 399 cases operated upon, which permits a follow-up of five years or more. These patients were treated between 1947 and April, 1951, and the position after April, 1956, was examined, giving a follow-up period of at least five years. All patients who have undergone lung resection are reported upon yearly by the chest physicians in charge, and thus a complete record of the results is available. Only two of the 399 cases have been lost sight of. The whole series of 1,575 cases has been utilized in studying the immediate complications of the operative treatment, and other sections of this series have been analysed 
TABLE I

RESULTS OF FIVE-TO-NINE-YEAR FOLLOW-UP AFTER RESECTION

\begin{tabular}{|c|c|c|c|c|c|c|c|}
\hline Operation & Total & $\begin{array}{c}\text { Mortality } \\
\text { (3 Months) }\end{array}$ & Well & $\begin{array}{c}\text { Evidence of Disease } \\
\text { or Disability }\end{array}$ & Dead & $\begin{array}{l}\text { Died Un:elated } \\
\text { Cause }\end{array}$ & L.S.O. \\
\hline Pneumonectomy & 129 & $6(5 \%)$ & $105(81 \%)$ & 5 active & 5 & 1 & 1 \\
\hline $\begin{array}{lll}\text { Lobectomy } & \ldots & \ldots\end{array}$ & 195 & $2(1 \%)$ & $175(90 \%)$ & $13\} 10$ active & 2 & 2 & 1 \\
\hline Segmental resection ... & 75 & $1(1 \%)$ & $67(89 \%)$ & $5\left\{\begin{array}{l}4 \text { active } \\
1 \text { disabled }\end{array}\right.$ & - & 2 & - \\
\hline Total & 399 & $9(2 \cdot 25 \%)$ & $347(87 \%)$ & $29(7 \%)$ & $7(2 \%)$ & 5 & 2 \\
\hline
\end{tabular}

in order that some specific problem may be answered.

The broad results of the five- to nine-year followup are given in Table I.

\section{IMMEDIATE MORTALITY}

The safety of lung resection as a surgical procedure must be estimated on these figures.

Immediate mortality has been reckoned as death within three months of the operation. In the 399 cases comprising the five- to nine-year follow-up series, the mortality rate was $2.25 \%$. We have subsequently lowered this figure and there have been 27 post-operative deaths in the full series of 1,575 operations, giving an overall figure of $1.71 \%$. The deaths are overwhelmingly in the pneumonectomy group, and this might be expected in view of the systemic effect of the long-term disease usual in these patients.

The cause of death is as in Table II.

TABLE II

CAUSES OF DEATH

\begin{tabular}{|c|c|c|c|c|}
\hline $\begin{array}{l}\text { Pulmonary embolus } \\
\text { Fistula and tuberculous br } \\
\text { Acute pulmonary oedema } \\
\text { Amyloid disease and urae } \\
\text { Acute staphylococcal pnet } \\
\text { Coronary thrombosis } \\
\text { Tuberculous pericarditis } \\
\text { Cerebral thrombosis } \\
\text { Secondary haemorrhage } \\
\text { Slipped ligature } \\
\text { Collapse on table }\end{array}$ & $\begin{array}{l}\text { hopr } \\
\cdots \\
\ddot{\text { onia }} \\
\ldots \\
\cdots \\
\cdots \\
\cdots \\
\cdots\end{array}$ & $\begin{array}{l}\ldots \\
\cdots \\
\cdots \\
\cdots \\
\cdots \\
\cdots \\
\cdots \\
\cdots\end{array}$ & $\begin{array}{l}\cdots \\
\cdots \\
\cdots \\
\cdots \\
\cdots \\
\cdots \\
\cdots \\
\cdots\end{array}$ & $\begin{array}{l}6 \\
5 \\
4 \\
3 \\
2 \\
2 \\
1 \\
1 \\
1 \\
1 \\
1\end{array}$ \\
\hline Total .. & $\cdots$ & $\ldots$ & $\ldots$ & $27(1.71 \%)$ \\
\hline
\end{tabular}

The number of patients dying from pulmonary embolism is surprisingly high. All these patients have been found to have evidence of deep femoral or pelvic thrombosis at necropsy. A possible explanation for this figure is that some of them had had long periods in bed with an insufficient period of mobilization to regain vascular tone before operation. All occurred in relatively young people and four of them before the fifth day. Active physiotherapy is a standard part of the pre- and post-operative treatment.
The other cause of death worthy of comment is that of uraemia and amyloid disease. The three patients had a pneumonectomy for a destroyed lung of long standing, and in such cases we have now learned the advisability of doing a complete renal function investigation. Where the function is poor, we have rejected the patient for operation. In doubtful patients we have deliberately maintained a rather high blood pressure with noradrenaline in order that the renal filtration pressure may not fall, for this seems to be the trigger setting off the anuria which, once established, appears so difficult to reverse.

\section{PYOTHORAX}

The most serious direct complication of the operation was the development of a pyothorax, not always with a fistula, and 20 occurred in the postoperative stage of the 399 operations, giving a figure of $5 \%$. Most of these appeared as staphylococcal infections in the first instance, and some later demonstrated tubercle bacilli in the discharge. It is somewhat difficult to assess the relative importance of these two organisms in the development of a pyothorax. Although the pleura can become grossly soiled with tubercle bacilli, it must be rare, and the usual cause of a post-operative pyothorax without fistula is infection with a coccus, usually a staphylococcus. In cases with a fistula, a sutured bronchus heals only partially due to inherent tuberculous disease, so that subsequently the passage of air into the pleural cavity carries staphylococci or other organisms in with it. Later the tuberculous process spreads along the walls of the cavity so formed. Occasionally a primary staphylococcal pyothorax, in which relief is delayed, will cause the formation of a fistula, although it will remain essentially a staphylococcal infection. In a simple coccal infection the pyothorax can usually be eliminated quickly with a thoracoplasty, but where a tuberculo-coccal infection is present the prognosis is much more serious, and the sinus may only be finally obliterated after a number 
of secondary plastic operations and a long ordeal for the patient.

Considerable significance should be attached to the late occurrence of pyothorax after pneumonectomy. Five of the 129 pneumonectomy patients developed pyothoraces between three and 15 months after operation. None of these patients had a post-resectional thoracoplasty and there was evidence of tuberculosis in the fluid in all cases. Drainage and subsequent thoracoplasty had to be performed in four, but one developed progressive disease in the opposite lung and subsequently died. The infection of healthy lung tissue by the spillover of pus from an intrapulmonary rupture of a tuberculous pyothorax is a very serious complication and is a potent reason why in later years we undertook thoracoplastic procedures in cases of pneumonectomy in an attempt to obliterate the pleural cavity. Total obliteration of a pleural cavity by thoracoplasty, however, requires an extensive operation even with a paralysed diaphragm, and the effect upon the costal movements of the opposite side may be serious in the older age groups.

TABLE III

INCIDENCE OF PYOTHORAX

\begin{tabular}{|c|c|c|c|c|}
\hline Operation & No. & $\underset{\text { thoraces }}{\text { Pyo- }}$ & Time & $\begin{array}{l}\text { 5-9 Year } \\
\text { Follow-up }\end{array}$ \\
\hline $\begin{array}{l}\text { Pneumonec- } \\
\text { tomy }\end{array}$ & 129 & 13 & 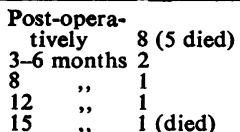 & $\left\{\begin{array}{l}7 \text { now well } \\
\text { but one } \\
\text { has an } \\
\text { external } \\
\text { sinus }\end{array}\right.$ \\
\hline Lobectomy & 195 & 5 & Post-operatively & $\begin{array}{l}\text { All treated } \\
\text { by thorac- } \\
\text { opl a s ty } \\
\text { and now } \\
\text { well }\end{array}$ \\
\hline $\begin{array}{l}\text { Segmental } \\
\text { resection }\end{array}$ & 75 & 2 & ", & $\begin{array}{c}\text { Treated by } \\
\text { thoraco- } \\
\text { plasty and } \\
\text { now well }\end{array}$ \\
\hline
\end{tabular}

Microfistulae

This minor complication is the most frequent after resection and usually of no serious consequence, but can be an annoyance both to the patient and the surgical staff. In this complication air leaks from the stripped surface of the remaining lung tissue after a segmental resection or a lobectomy where the neighbouring lobes have been congenitally fused. Small bronchiolar communications exist across these segmental planes and congenital fusions, and can be easily demonstrated by clamping a segmental bronchus and then inflating the lobe. The obstructed segment is rapidly filled from the neighbouring segments. This phenomenon has been fully described by Churchill (1953). The previous existence of an extensive pneumonitis in the segment usually results in the sealing off of these communications, and the comparative rarity of this complication after segmental resection for bronchiectasis is explained on this basis. Stripping of a segment across the intersegmental plane will leave a number of tiny holes in the walls of the bronchioles running along the plane and it is from these that air persistently leaks. Picking up the edges of the leaking bronchiole with fine forceps and ligating usually suffices to close them. Others will usually close with blood clot becoming adherent to the edges. One or more may continue to leak slightly for some days and require continuous relief of pressure in the pleural cavity. It is not unusual for all to appear to be well for some days, but as the lung expands further to fill the thoracic cage the plug obstructing the bronchiole separates (usually between the fifth and tenth day) and the patient is found to have more air in the chest and needling is required. It is usual for pyrexia and some discomfort in the chest to be noted with the onset of the air leak.

It is rare for infection to supervene in this type of case, but if the patient carries staphylococci in the bronchial tree enough organisms might be transferred to the pleural space for the ultimate development of a pyothorax. This type of infection is more prone to occur if there is already a source of staphylococci in the ward and the airborne flora of this type are increased. We believe it advisable that all patients who are being prepared for operation in the tuberculosis wards should have their sputum examined for staphylococci in the pre-operative stage, and, if found, a course of the appropriate antibiotic given until they disappear from the sputum.

The persistence of a pneumothorax, particularly if localized, will result in uneven expansion of the lung. Adhesions will limit expansion of some of the lung tissue, while the free areas will eventually over-expand.

Our treatment of the persistent pneumothorax is primarily by an indwelling needle or small cannula (Morland's needle), which is connected to an underwater-seal bottle. The first or second interspace anteriorly is usually a suitable site. The needle is changed to a new site (say $1 \mathrm{~cm}$. away) every two days and $1 \mathrm{~g}$. streptomycin injected into the pleural cavity on each occasion. The needle-drainage is maintained until no bubbling is seen in the water-bottle on hard coughing.

We have sealed a microfistula in many cases by the direct injection of $20 \mathrm{ml}$. of the patient's own blood (withdrawn from an arm vein) into the persistent pleural space if it is comparatively localized and the fistula is likely to be on the floor 
of the space. This procedure is repeated daily for three to four days. It is presumed that the clot developed seals the opening and eventually organizes in situ.

A persistent microfistula may eventually require re-exploration with decortication of the lung. Although the fistula may be demonstrable on the lung surface, on increasing the intrabronchial pressure after decortication and expansion of the lung it usually becomes undefinable. If there is only a small apical air space a localized thoracoplasty to permit approximation of the walls will usually seal the fistula.

One of us (J. K. B. W.) investigated the incidence of microfistulae in relation to the use of pneumoperitoneum, phrenic crush, the number of drainage tubes, suture of raw surfaces of lung and concomitant thoracoplasty in a series of 333 cases in which a "leak" might be expected.

This series consisted of resection of one, two, or three segments of the upper lobe, of the upper lobe segments and the apical lower, and of the complete upper lobectomy with apical lower segments. In 66 patients $(19.0 \%)$, the leak of air persisted more than 48 hours.

Concomitant thoracoplasty appeared to be the most significant factor in reducing the persistence of microfistulae. Where no thoracoplasty was performed microfistulae persisted for more than 48 hours in $24.1 \%$ of the patients, but when thoracoplasty was undertaken the microfistula rate fell to $14.6 \%$.

The use of two drainage tubes, one of which permitted escape of air from the apex of the chest, and suture of raw lung surfaces were both important factors in promoting rapid sealing of leaking lung tissue. High negative pressure suction has not been used to any great extent.

\section{Reactivation of Disease}

The development of new areas of disease in the post-operative phase or later appeared to be rare unless a tuberculous pyothorax had ruptured into the lung. Evidence of new activity was almost uniformly found in areas that had already been the site of disease, but which had been assumed to be quiescent or healed. This assumption was made radiologically on reactivated disease in the contralateral lung. On the ipsilateral side, additional confirmation was given by the operation notes describing palpated nodular areas which had been left behind as supposedly healed or likely to heal in the near future. The rare, completely new infiltrations appeared to be bronchial spreads from
TABLE IV

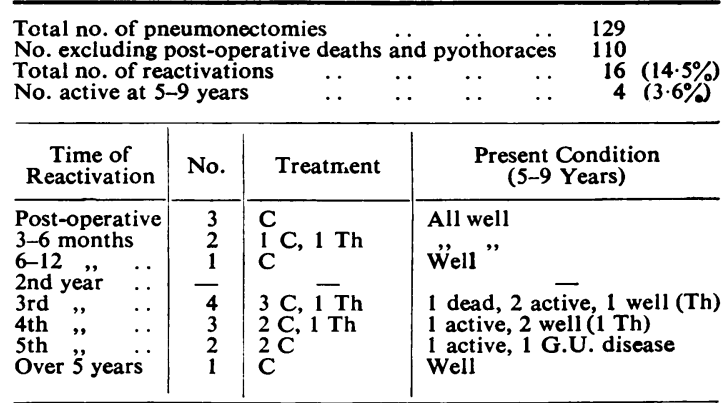

(C=Chemotherapy. $\quad \mathrm{Th}=$ Thoracoplasty. $\mathbf{R}=$ Resection.)

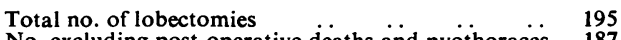

No. excluding post-operative deaths and pyothoraces 187

\begin{tabular}{llllll} 
Total no. of reactivations &. &.. &.. &. & $26(13.9 \%)$ \\
No. active at 5-9 years &.. &.. &. &. & 10 \\
\hline
\end{tabular}

\begin{tabular}{|c|c|c|c|}
\hline $\begin{array}{c}\text { Time of } \\
\text { Reactivation }\end{array}$ & No. & Treatment & $\begin{array}{l}\text { Present Condition } \\
\text { (5-9 Years) }\end{array}$ \\
\hline $\begin{array}{l}\text { Ipsilateral: } \\
\text { 1st year }\end{array}$ & 8 & $\begin{array}{l}4 \mathrm{C}, 1 \mathrm{Th}, 1 \mathrm{R} \\
2 \text { refused } \\
\text { treatment }\end{array}$ & $\begin{array}{l}6 \text { well } \\
2 \text { active (refused treatment) }\end{array}$ \\
\hline $\begin{array}{lll}\text { 2nd } & , & \ldots \\
\text { 3rd } & \# & \cdots \\
\text { 4th } & \# & \cdots \\
\text { 5th } & , & \cdots\end{array}$ & $\begin{array}{l}2 \\
4 \\
1 \\
1\end{array}$ & $\begin{array}{l}2 \mathrm{Th} \\
2 \mathrm{C}, 2 \mathrm{R} \\
\mathrm{C} \\
\mathrm{C}\end{array}$ & $\begin{array}{l}\text { Well } \\
3 \text { well, } 1 \text { active (C) } \\
\text { Well } \\
\text { Active }\end{array}$ \\
\hline 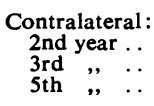 & $\begin{array}{l}2 \\
3 \\
2\end{array}$ & $\begin{array}{l}2 \underset{\mathrm{C}}{\mathrm{C}}, 1 \mathbf{R} \\
2 \mathrm{C}\end{array}$ & $\begin{array}{l}1 \text { well, } 1 \text { active } \\
2 \text { well, } 1 \text { active (C) } \\
2 \text { active }\end{array}$ \\
\hline 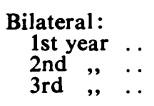 & $\begin{array}{l}1 \\
1 \\
1\end{array}$ & $\begin{array}{l}\mathrm{C} \\
\mathrm{C}\end{array}$ & $\begin{array}{l}\text { Uncontrollable progressive } \\
\text { disease } \\
2 \text { active, } 1 \text { dead }\end{array}$ \\
\hline
\end{tabular}

Total no. of cases of segmental resection

No. excluding post-operative deaths and pyothoraces 75

\begin{tabular}{llllll} 
No. excluding post-operative deaths and pyothoraces & 72 \\
Total no. of reactivations &. &. &. &. & 10 \\
\hline
\end{tabular}

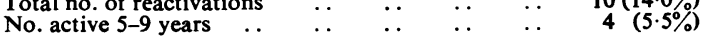

\begin{tabular}{|c|c|c|c|}
\hline $\begin{array}{c}\text { Time of } \\
\text { Reactivation }\end{array}$ & No. & Treatment & $\begin{array}{l}\text { Present Condition } \\
\text { (5-9 Years) }\end{array}$ \\
\hline 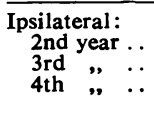 & $\begin{array}{l}2 \\
3 \\
2\end{array}$ & $\begin{array}{l}2 \mathrm{C} \\
3 \mathrm{C} \\
1 \mathrm{Th}, 1 \text { refused } \\
\text { treatment }\end{array}$ & $\begin{array}{l}1 \text { well, } 1 \text { active } \\
2 \text { well(Th), } \ddot{i} \text { active }\end{array}$ \\
\hline $\begin{array}{l}\text { Contralateral: } \\
\text { 2nd year .. } \\
\text { 3rd }, \quad .\end{array}$ & $\begin{array}{l}1 \\
2\end{array}$ & $\begin{array}{l}\mathrm{C} \\
2 \mathrm{C}\end{array}$ & $\begin{array}{l}\text { Well } \\
1 \text { well, } 1 \text { active }\end{array}$ \\
\hline
\end{tabular}

Although the total numbers are not large, it is interesting to note that the incidence of reactivation in the three operation groups works out almost the same.

\begin{tabular}{|c|c|}
\hline $\begin{array}{l}\text { Pneumonectomy } \\
\text { Lobectomy . . } \\
\text { Segmental obstruction }\end{array}$ & $\begin{array}{ll}. & 14.5 \% \\
. & 13.9 \% \\
. & 14.0 \%\end{array}$ \\
\hline Time of Reactivation & No. \\
\hline $\begin{array}{l}\text { 1st year } \\
\text { 2nd ", } \\
\text { 3rd ", } \\
\text { 4th ", } \\
\text { 5th ", } \\
\text { Over 5' years }\end{array}$ & $\begin{array}{r}15 \\
8 \\
17 \\
6 \\
5 \\
1\end{array}$ \\
\hline
\end{tabular}


reactivation of old disease in another area. Reactivation must be considered a failure of treatment, but frequently other factors were of paramount importance. Many episodes were in unsatisfactory or undisciplined patients, and in others the social and economic background militated against the expected healing of a retained focus.

In the group of 399 cases under study, all nontransient increases in radiological shadows were considered as reactivations, whether the sputum showed bacilli or not.

The number and time of the reactivations were as in Table IV. (Cases of spread of disease associated with rupture or possible rupture of a pyothorax are not included, and it has thus been deemed advisable to exclude all cases of pyothorax and post-operative deaths, leaving a total figure of 370 cases.)

The number of reactivations shows a peak about the third year after operation and a gradual falling off thereafter, suggesting that resistance to the disease becomes more permanent. Treatment of the reactivated disease was mainly by chemotherapy, but thoracoplasty and further resection were undertaken in selected cases. Out of the $\mathbf{5 2}$ reactivated cases, $34(65 \%)$ appear to have been successfully treated.

It should be mentioned again that the operations in this group under review were done without thoracoplasty (although a temporary space reduction was produced by a phrenic crush and a pneumoperitoneum). Three main types of reactivation appeared to be present on re-analysing the films. First, the enlargement of diseased areas in apical lower segments after lobectomy associated with apparent hyperexpansion of this area into the apex of the chest: such areas were judged to be healed or nearly healed by palpation at the time of operation and were of millet-seed or fibrotic consistency. Secondly, a similar hyperexpansion of the apex of the contralateral lung occurred with traction of the trachea to the operated side after lobectomy or segmental resection, which has been responsible for the reactivation of old disease in that area. Thirdly, the reactivation in the contralateral lung in the pneumonectomy cases was in association with a hyperexpanded lung, and this factor could not be excluded.

It appeared to us that more efficient space reduction to prevent over-expansion of the remaining and contralateral lung might be a desirable feature, as at that time the use of very long-term chemotherapy after operation was not considered practicable.

The place of space reduction after resection is a matter of varied opinion. On the functional aspect any permanent collapse procedure on the thoracic cage will reduce the ventilatory capacity of the lungs. There is no point in returning this figure to the pre-operative level after resection of an area of lung tissue, if it is only achieved by the distending of the lung tissue left behind, as the oxygen uptake is not thereby increased. The maximum oxygen uptake of lung tissue can be obtained by maintaining the lung or lobe at its normal size, provided that the lateral portion of the chest wall and diaphragm move adequately and pleural thickening is not severe.

The only statistical evidence we have that space reduction is advisable or not is as in Table $\mathrm{V}$. Routine thoracoplasties on lobectomies were only started in 1952, thus we only have a three-year follow-up of such cases, but these figures can be compared with the three-year follow-up states of the 1947-1951 lobectomy cases, and appear to have some significance. It is believed that the type of case on which resection was undertaken had not changed in this period.

TABLE V

VALUE OF SPACE REDUCTION

\begin{tabular}{|c|c|c|}
\hline \multicolumn{2}{|c|}{ Lobectomy } & Reactivation in 3 Years \\
\hline $\begin{array}{l}\text { Without thoracoplasty } \\
\text { With , }\end{array}$ & $\begin{array}{l}195(1947-1951) \\
58(1952)\end{array}$ & $\begin{array}{r}19(9.8 \%) \\
2(3.5 \%)\end{array}$ \\
\hline
\end{tabular}

\begin{tabular}{|c|c|c|c|c|c|}
\hline \multicolumn{5}{|c|}{ Segmental Resection } & Reactivation by 1956 \\
\hline $\begin{array}{l}1952 \\
1953\end{array}$ & $\begin{array}{l}\text { Without } \\
\text { With } \\
\text { Without } \\
\text { With }\end{array}$ & $\begin{array}{l}\text { cor } \\
\text {," } \\
\text { ", }\end{array}$ & & $\begin{array}{l}96 \\
19 \\
61 \\
48\end{array}$ & $\begin{array}{l}6 \\
0 \\
5 \\
5\end{array}$ \\
\hline
\end{tabular}

The figures for segmental resection, we think, would give no support in either direction.

Although the reactivation of disease is probably the most important factor, there are other reasons why space reduction should be considered. The long-term effects of over-expansion of lung tissue are difficult to determine, but, judging by the bronchographic appearances in cases of nontuberculous bronchiectasis with a collapse of the left lower lobe and an overdistended lingula, the resulting pulmonary structure appears to be considerably disorganized. The effects on the circulatory system in the lung may be longer in becoming manifest, but the loss or elongation of the capillary bed is likely to be disadvantageous. There is some evidence to suggest that a residual space containing fluid may ultimately become infected, and for this reason is best obliterated.

Furthermore, when a segmental resection has been done or a lobectomy has required a large 
strip off the adjacent lobe, if no space reduction is performed the expansion of the remaining lung tissue required may be so great that small leaks appear in peripheral bronchioles and an air-space develops two to three weeks later as described earlier.

As a result of our experiences our views on space reduction now stand as follows:

In pneumonectomy, lobectomy, or the removal of two or more segments, a corrective thoracoplasty (usually with resection of the first rib) is done either at the time or three or four weeks later, depending upon the condition or age of the patient. With removal of one segment only, no corrective thoracoplasty is employed. If there is evidence of disease at the opposite apex, a portion of the first rib is removed to prevent tracheal deviation. The extent of thoracoplasty depends upon the amount of lung tissue removed.

The type of thoracoplasty used has varied. Despite the immediate advantages of fixing the apex of the chest with one of the roof types of thoracoplasty, we still believe that the end-result of simple rib resection with its convex inner surface conforms best to the natural shape of the remaining lung. Paradoxical movement even in the more elderly patients is not a serious factor if the chest is adequately splinted externally.

\section{Older Age Groups}

With the steady increase of the older age groups being presented for surgery, the problem arises as to the best form of operation for those over 50 years of age. These people have usually had tuberculosis for very many years and the lung changes are severe, not only in the local area of active disease, but as a result of numerous spreads into other areas in the past. Pulmonary function on the whole is poor and the cardiovascular condition is often dubious. It is doubtful whether healing in these very chronic forms of tubercle ever does take place with collapse therapy. Resection offers a better chance of a cure, but is a more formidable procedure in these people than a thoracoplasty. Out of our total series $(1,575)$ we have under-

TABLE VI

RESULTS IN PATIENTS OVER 50

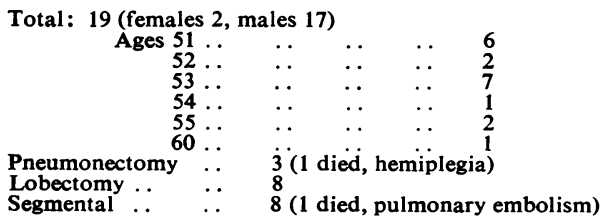

taken resection in 19 patients over the age of 50 .

Four patients developed empyemas; all drained. Three required thoracoplasty, but are now healed. The empyema rate of $20 \%$ is of importance and there is little doubt that the incidence of infection is generally higher in this age group. Corrective thoracoplasties in our experience are better performed as a second operation in this age group. If the pulmonary function is in doubt in these patients, we perform a thoracoplasty in preference to a resection operation.

\section{Younger Age Group}

At one time we held the view that resection of lung below the age of 20 was associated with a higher incidence of reactivation of the disease, particularly in view of the instability of the disease in the late teenage.

Thirty-six patients of the 399 were under 20 and five developed pulmonary reactivation in the five years. Three are now well, one is active with genito-urinary disease, and one died with a rupture of a delayed tuberculous empyema and extensive disease in the opposite lung.

Reactivation rate below age $20 \quad \ldots \quad 14 \%$

Reactivation rate over age $20 \quad \ldots \quad 14 \%$

Eighty-three patients (50 women, 33 men) under the age of 20 were operated upon up to April, 1954 , giving a two- to nine-year follow-up with the results set out in Table VII.

\section{TABLE VII}

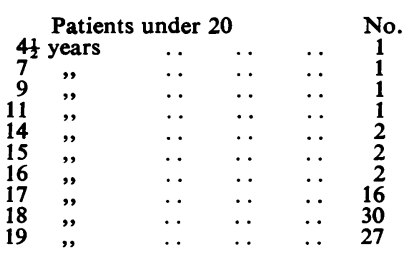

All are alive to date except one. Eleven have reactivated during this period $(13 \%)$. One has developed genito-urinary disease From these figures it would seem that resection can be carried out in this younger group without fear of increased incidence of reactivation, provided that the cases are selected with care and only chronic forms of disease are operated upon.

\section{Home Treatment}

It has been our policy to send patients to their homes six weeks after operation to continue under the care of the chest physician, provided the home conditions are satisfactory and the disease that has 
been left behind appears safe. If the remaining disease is dubious or home conditions are unsatisfactory or the patient is an undisciplined type of individual, then the patient is retained on the medical side until considered fit for discharge. This policy was dictated in the first instance by the lack of sanatorium accommodation, but we have continued it as we believe that the patients have not suffered unduly, and, as the likely cause of a positive sputum has been removed, there is little danger from the infective point of view.

We have not been able to prove this point on our figures, because although only 15 of the 52 reactivations occurred in the first year, yet it might be stated that the later breakdowns might not have occurred if the patient had been kept under hospital care for some months after the operation. Of the 15 patients breaking down in the first year, six were sent home after six weeks, eight were retained in hospital, and one took her own discharge.

\section{Conclusions}

Although the rapidly changing face of the treatment of pulmonary tuberculosis makes the accurate assessment of one particular episode in the course of therapy virtually impossible, certain broad conclusions can be drawn, particularly if the follow-up study is long enough.

First, we believe that we can accept resection treatment for that portion of the disease which cannot be healed by rest and chemotherapy as a reasonably safe line of treatment, with a mortality of under $2 \%$. Compared with thoracoplasty this means that a longer period of training of junior staff is required before they can safely undertake this type of operation.

Secondly, except for the minor segmental excisions, we believe that a space-reducing operation either at the same time or as a second procedure is obligatory. This opinion may be altered when we see the results of chemotherapy given for one to two years after operation. Our experience has disproved the hope that we had at the beginning that the thoracic cage could be left intact.

Thirdly, $87 \%$ of patients operated upon are well and free of any evidence of active disease at the end of five years. Nine per cent. still have active tuberculosis or have died of the disease in this period. We believe that resection treatment has justified itself.

Our most sincere thanks are due to Mrs. Anthony, who has maintained the follow-up organization of these patients with undefeatable persistence. Without the information and co-operation so readily given by all the chest physicians concerned, this review would not have been possible, and to them we are most grateful. Finally, we should like to express our appreciation of the work of the nursing staff of Aintree and Broadgreen Hospitals, and any success we may have had has been in great part due to their care.

\section{REFERENCES}

Bickford, B. J., Edwards, F. Ronald, Esplen, J. R., Gifford, J. Hamilton, Mair, A. M., and Thomas, O. F. (1951). Thorax, 6, 25.

Churchill, E. D. (1953). Ann. Surg., 13:, 1. 